\title{
Language and Text as Generic Components of the Cultural Semiotic Framework
}

\author{
Elena Skorohodova ${ }^{1}$, Larisa Aleshina ${ }^{1}$, Elena Sevryugina ${ }^{1}$, Irina Tortunova ${ }^{1} \&$ Larisa Selezneva $^{1}$ \\ ${ }^{1}$ Russian State Social University, Russian Federation \\ Correspondence: Elena Skorohodova, V. Pika 4, Moscow, 129226, Russian Federation.
}

Received: January 20, 2015 Accepted: April 29, 2015 Online Published: July 30, 2015

doi:10.5539/ass.v11n19p221 URL: http://dx.doi.org/10.5539/ass.v11n19p221

\begin{abstract}
This article is devoted to a number of humanitarian disciplines of the problem of the text in its modern interpretation, and the problem of interpretation of meaning in contemporary social and cultural space. The XX-XXI century became the era of "dialogue of cultures and intercultural communication; force us to rethink the historical-cultural process and spiritual heritage of the past.
\end{abstract}

Keywords: culture, text, context, sign, semiotics, encoding, transcoding, semiotic mechanism of culture, invariant patterns, universal cultural meanings

\section{Introduction}

The cultural consciousness of a modern person is a special phenomenon in the context of which the understanding of many fundamental logical, conceptual and aesthetic categories has transformed substantially. For example, such concepts as language, speech, text, sign, and semiotics have been interpreted in a newer and broader way. According to S. Bibler, the author of the famous 'dialogues of cultures' concept, the XX-th century led us to the fundamentally new forms of "consciousness determination", when it is impossible to exist within a single cultural formation due to the constant series of wars, migrations, social and natural disasters (Bibler, 1989). A continuous and chaotic interaction of different cultural traditions has resulted in global integration of semiotic systems, which we regard as universal languages of different kinds of art and various forms of social consciousness. It also led to understanding culture as a multidimensional intertextual space, which we continuously interact with. In this sense, we can no longer rely on traditional definitions of such concepts as "language" and "text", according to which these categories are treated as purely linguistic entities, as ways of reality verbal reflection. The very notion of semiotics has been changing in the course of developing the modern scientific thought.

\section{Methodology}

For the deep and comprehensive examination of the issue, connected with text and language as generic components of semiotic mechanism of culture, we rely on such terms as semiotic sphere, semiotics of culture, deciphering the meanings and characters. Based on the data of the contemporary Russian culture dictionary, we will identify a semiosphere as a semiotic space, which has, essentially, the same object as culture and as a necessary precondition of the verbal communication (Rudnev, 1997).

The semiotics of culture, which, according to Y. M. Lotman, "was interpreted as linguistic methods' application to objects excluded from the traditional linguistics" (Lotman, 2000), can be taken as a basis for semiotic sphere as a broader and more generic concept.

Deciphering the meanings and characters, double text coding, where it becomes a carrier of cultural information, involves its initial existence of the "natural language" signs, and its following link to other cultures' signs or to various arts languages. For example, the text submitted in verbal signs, becomes a culturally relevant informative field when it connects with the artistic thought of some writer, artist, sculptor, etc.

To illustrate the idea and to build the evidence base, we use the texts of Russian poets and writers (Tolstoy, Tyutchev, etc.) and analyze them at the level of broad socio-cultural as well as of individual-copyright context. The multilevel contextual analysis is the main methodological tool of our study. 


\section{Results}

The comprehensive analysis of the text as a universal cultural and linguistic category can reveal at least two basic approaches to its study. The first, a traditional one, typical for the Russian linguistics, interprets a text as "an ordered set of sentences, united by different types of lexical, grammatical and logical connection that can transmit information, organized and directed in a certain way" (Turayeva, 1986).

The second approach gives a much broader interpretation of the text, bringing it close to the modern notion of "discourse", and involves several levels of this logical notional category's treatment:

1. Text (discourse) as verbal communication, a dialogue, a developing dynamic structure.

2. Text (discourse) as an expanded sense in a speech recipient's mind.

3. Text as a universal cultural code, a mechanism of culture, which allows identifying and analyzing multiple cultural meanings, born at the crossroads of different eras.

The second approach also has a large number of schools and directions related to different methods of text analysis: content analysis, discourse analysis, the study of discourse words-references, etc.

From this point of view, any object of culture and society, any work of art may be called a text. We take this approach as a fundamental one for our article.

\section{Discussion}

\subsection{Text Research History in Modern and Foreign Linguistics}

The emergence of linguistic text theory generally dates from 50-70 years of the 20th century. The study of fiction texts played a fundamental role in the development of the theory of text, matching philology and rhetoric ideas and promoting them into the text theory. Thus, in the study of poetic language program, suggested by G.O. Vinokur in an article of the year 1946, the ultimate goal of exploring the poetic language basing on the text materials is labeled as "the artist's personality, his ideological and artistic intent, the poetics of the work or the collection of works" (Vinokur, 1991).

In the first half of the 20th century L. V. Shcherba in the article "On the threefold capacity aspect of language phenomena and an experiment in linguistics" gave the texts, at the first glance, the auxiliary role, treating them similarly as some linguistic material, the essence of which is "being able to produce" "all the language values that we operate in a vocabulary and grammar" (Scherba, 1974). However, the scientist's idea is quite right: it fixed the text status of being the source reality of linguistic research.

The research by N. S. Pospelov had a notable value in text theory formation in the Russian science in 40-50-ies of the 20th century; the ideas were presented in a series of articles and monographs on the syntactic structure of poetic works of Alexander Pushkin (Pospelov, 1960). In the foreign linguistics at that time the idea of "sentence community" developed (Boost, 1955), as well as the idea of discourse (Harris, 1952, pp. 1-30), utterance (Skalichka, 1967, pp. 119-127), etc.

Pospelov's research actually proved that there is something "over the sentence" (= over the phrase) in the text. Therefore, the theoretical results obtained by N. S. Pospelov, largely defined the understanding of the text and many of the directions in its research in 60-70-ies of XX century.

Further on, in the modern humanities several areas in the text study appear. M. M. Bakhtin formulated the following thesis: "The phenomenon of text life, that is its true essence, always develops at the border of two minds, two subjects" (Bakhtin, 1997). Thus, a future theory of text got its key problem-the problem of the text life.

The main achievements of the 60-70-ies are associated with the search of the text essence-recognition of its place in the system of language/speech (text is the highest syntactic unit), its qualification as a syntax sign, determination of its hierarchy, its content and expression aspects, it study from the functional and from the modeling perspective, etc.

At the present stage of the linguistic knowledge development, a text is actively involved into the scope of the study by a whole range of Humanitarian sciences: semiotics, pragmatics, hermeneutics, anthropology, theory of operation, etc. The consequence is a phenomenon, qualified by P. Rieker as the conflict of interpretations; the resurrection or the emergence and development of several new branches of language science, including the theory of communication, linguo-pragmatics philological hermeneutics, discursive linguistics etc. The central sense forming category of humanities is the unity "people and their language "in philosophical reflection of this phenomenon. Many modern Russian and foreign linguists, such as D. Tannen (2012), K. Krippendof (1980), N. 
Garfunkel (1967) pay considerable attention to the modern methods of text analysis, connected with its pragmatic and communicative nature. Of great interest are the current studies that focus on the study of the separate text components, which have a particular importance in the process of understanding and cooperation between the participants of the speech act, establishing external communication (Borisova, 2014; Rudnitskaya \& Pletneva, 2014, pp. 72-81).

\subsection{Text as a Universal Semiotic Mechanism of Culture. Y. M. Lotman's Concept}

Y. M. Lotman made a significant contribution to the development of modern ideas about culture, language and iconic; he became the founder of the Tartu semiotic school, the author of the semiosphere doctrine. For greater visibility, Lotman gives a figurative definition of "semiosphere", comparing it to the museum, which displays the exhibits from different epochs in different show rooms. (Lotman, 2000). Insight into the essence of the proposed by Y. M. Lotman association can explain such categories as "language", "culture" and "text" in their unbreakable unity. Moreover, the notions of "language" and "text" when widely understood become an integral part of the culture, outside of which it cannot exist at all as if being deprived of its tools.

The "unified fabric" of culture can be woven from the finest iconic elements, among which there are both changing with the era ones and invariant components. Storage, transfer and conversion of cultural senses in the context of new cultural traditions, as well as the creation of the new cultural space are possible only due to language and text. But the perception of the text itself should not be traditional, and Y.M. Lotman wrote about it in his selected articles, noting: "to define this message as "a text ", it should be encoded at least twice" (Lotman, 1992, pp. 129-132).

For example, the antithesis of "war" and "world" in a variety of its senses and artistic values doesn't work outside the main context, and only after reading the content of the novel by Leo Tolstoy, we can "read" and see all the hidden cultural information. We can appreciate the full complex of author's views on the true and the false, the beautiful and the ugly, of the chaos and the harmony, the sublime and the basest. At the same time, this cultural context was based on a variety of other contexts, united into a complex artistic intent. Could Tolstoy write his most significant work, having not absorbed the traditions of his historical period, as well as the age-old folk cultural traditions? The so-called "citation" as a means of a literary text organization can be widely understood. Namely, as the clash and interaction of different cultural codes in their mutual conversion and disclosure of previously implemented, but now actualized meanings. We reconsider the experience of the preceding ages and introduce it into the modern cultural contexts. This is the way mechanism of culture is activated, and the ways new cultural forms appear. This process, as Lotman argues rightly, is continuous. Moreover, it is multidirectional: both horizontally (as a process of culture codes of various regions exchanging), and vertically (as the interaction of cultures of different periods), both at the level of the individual adoption of the culture by its native speakers, and within the new cultural values creation. Thus, any work of literature, painting, sculpture, architecture, any public tradition, any set of behavior reactions is a text which we enter for the continuous interaction and where culture functions. It is important to understand here that this text contains certain references to other, no less important texts that make up the united structure with the source material, yet the heterogeneous one.

In the light of the above-mentioned ideas, and developing Lotman's thoughts, one could summarize that "the text in front of us is not a message in some language, but a sophisticated device that stores multiple codes that can transform messages and generate new ones; it's an information generator, which has features of the intellectual personality. According to this, the idea of the text-user and the text' relationship is changing. The changing instead of the formula "the user decrypts the text" a more accurate one appears: "the consumer interacts with the text". They come in contact. The process of the text decryption becomes extremely complex, loses its single and finite nature, approaching to the familiar acts of human semiotic communication with another autonomous semiotic personality" (Lotman, 1996).

\subsection{Cultural Senses in the Fiction Texts. Levels of Semantic Interpretation of an Artistic (Poetic) Text}

An inadvertent question might arise: which culture codes and hidden meanings can open up to us in the text? Their amount is huge; some 'senses' appear under the influence of the previous epochs, others are made by the certain socio-cultural context, others (if we are talking about art) by the characteristics of individual author's perception and idiostyle. You can state a direct relationship between the number of hidden cultural meanings of artworks and the talent of the author, creator. For example, if we talk about poetry, then a great poet's work is absolutely full of such senses. To illustrate this, let's take a poem by F. I. Tyutchev as an example "There is a certain hour in the night ...":

There is an hour at night when the entire world is silent. 
Sights are seen. Miracles are done.

The living horse and chariot of creation

Stampede the heavens in unbridled run.

Night draws in, thick Chaos heavy on the seas.

Oblivion presses on the earth, like Atlas.

Alone on the Muses' virgin soul

In seer-dreams the gods inflict unease/translation by F. Jude/

To begin with, the proper interpretation of this little poem's semantic connotation is only possible if the reader is provided with a certain cultural preparation. In particular, he must be aware of some facts of the poet's biography, his worldview, literary and philosophical predilections of his era. Actually a potential reader should be a good erudite in general and be acquainted with the basics of common historical and cultural process. So, let's try to identify the basic levels of the text semantic comprehension. On the first, relatively surface level, we see that the author is a poet, the poet-philosopher, who is able to appreciate the beauty of the night and see some sacred meaning in it. Tyutchev's contemporaries and researchers of his creativity called the poet "a singer of the night ". But here the question arises: where does such an expressed interest in the night time come from? When answering this question, we will discover another deeper sense of the poem, or rather one of its cultural codes. First, Tyutchev lived in an era that is rightfully considered the age of religious-philosophical thought climax. During this period, many mystic destinations appear, 'sofiynost' for example, actually prevailed. Its essence was to find the World soul, Universal harmony, and "the dark root of existence". The poet is looking for this root, this divine truth in the dark time of the day, in the mysteries and riddles of the night. Secondly, Tyutchev considered himself a pantheist and a follower of the ancient classical philosophers' teachings. Probably the poet adapted Plato's idea of the transformed Eros through the Christian teachings --a beauty ideal, born because of the chaos genesis. The word "chaos" becomes a key one in the poet's works, and obtains the sacral-religious and philosophical meaning. The antique, Greek layer of Tyutchev's lyrics is another significant cultural code, another semiotic system. Images of Greek mythology literally permeate the whole poem: (the alive chariot of the world), (unconsciousness, like Atlas, presses the land", "the night gets thicker like Chaos on waters". As for the latter poetic image, it deserves special mentioning: it encodes not only the fundamental notion of Greek mythology and philosophy, but also the main category of all mythological systems of the world, drawing the reader simultaneously to eschatology and cosmology. Chaos can be interpreted as the end of the world, the collapse of matter, still mentioning the waters is not accidental. In all the ancient mythologies of the world, water is referred to as the fundamental principle of being, the original form of the universe, from which all things arose. In this sense, the "chaos on the waters" is a primary form of existence, or rather a link where the beginning and the end of the world meet: chaos represents the end of existence, and it marks the beginning of new, emerging forms of existence. From here, we can deduce what enormous cultural layer, what important ancient culture code values are reflected in Tyutchev's poetry, even within such a small poem. Even that does not exhaust all the hidden meanings of the work.

\subsection{Text and Literary Tradition}

Table 1.

\begin{tabular}{ll}
\hline M. M. Kheraskov (Night meditation) & F. I. Tyutchev (Just as the ocean curls...) \\
\hline & Just as the ocean curls around earth's shores, \\
I am led to the meditation & Our earthly life's embraced by dreams. \\
When the horizon is covered & Night comes and brings the element \\
By a trembling procession of the Moon; & And night intensifies its roars. \\
All nature is sleeping in silence & Now, there's its voice, persisting, pleading. \\
The eye does not see, the ear does not hear, & The magic skiff is straining to be free. \\
But the silence seems to whisper & Now out it goes, its human cargo leading \\
That there is something higher & Into the dark, immeasurable sea. \\
Which makes all earthly things & Heaven's vault's aflame with starry glory. \\
Sleep in a saving dream & From every side, as long as we're afloat, \\
When a star throne appears & its mystery staring from the deeps, \\
& That fiery chasm engulfs our boat. \\
\hline
\end{tabular}


We mentioned only two contexts: the context of the era in which Tyutchev lived and the cross-cultural context. However, there are other levels of semiotic interpretation of the text. In the field of verbal arts, if the text is consideration as an epistemological and cultural category, the notion of literary tradition becomes most significant. Thus, the predecessor of Tyutchev in Russian philosophical poetry is M. M. Kheraskov, who lived in the 18th century. He was one of the first to open the small lyrical genres and "poetry of night". Some similarities in the themes of these poets prove that Kheraskov influenced Tyutchev's creativity. One can even illustrate this by comparing the poem "Night meditation" by Kheraskov and Tyutchev's poem "Like the ocean embraces the earth". The similarity of ideas, feelings, even the frequency of keywords and phrases will be apparent.

Both Kheraskov, and Tyutchev use such similar expressions as: 1) "a star throne" and "the vault of heaven, the burning star of glory); 2) "the whole nature is sleeping in silence" and "the earthly life is encircled by the dream". The analyzed Tyutchev's poem "There's a certain hour in the night ..." also has such images as: (the alive chariot of the world), (the sanctuary of heaven", "prophetic dreams", etc. However, with the seeming thematic proximity of these authors, there are also important differences explained by the different cultural contexts. If we read both of these poems carefully, we will find the following: 1) Kheraskov's poem seems more "defined" by genre, it resembles an elegy-a sad song, "meditation" (it leads me to the meditation...) 2) Unlike Tyutchev, who is in the process of merging with "the mystical night" (and we're sailing surrounded by the inflamed abyss...) Kheraskov is only a bystander, the philosopher- representing the author's position. What can it tell us about? First of all, that Kheraskov is the poet of his era: gallant, sophisticatedly gourmet, where the storms of passion are always hidden under the cover of the external serenity. Tyutchev, on the opposite, was born in an era when the intimate, profound lyricism is in its heyday, when forms of poetry lack the "defined" style and imitative character, and the author's identity is revealed in all its variety and inconsistency. Thus, we have described the difference between the two cultural traditions. Yet one must realize that in Tyutchev's poetry (in particular, in one of his poems) two cultural contexts are opposed and by interacting with each other, they have given birth to a new form of artistic expression. Tyutchev as a poet of his era creates a deeply philosophical work in which he gives a mystical interpretation of nighttime and describes the nature of its impact on the lyrical hero. At the same time, the poem also resembles an elegy, a night meditation in its form. The ceremonial vocabulary is also present: "the sanctuary of heaven", "the burning arch of star glory", (inflamed abyss) and so on. The lyrical hero's emotionally high mood while beholding the grand pictures of nature (in this case, a night picture), awareness of one's insignificance in the face of God as a higher power, the desire to discover the mystery of existence- all these are certain cultural meanings, forming the basis of the cultural worldview of the 18th century. It's appropriate to remember here the lines from an ode by Derzhavin, "I am the King, I am the slave, I am the worm, I am the God."

This entire cultural heritage was accepted by Tyutchev and "coded" in his works, along with specific, purely personal philosophical worldview of the poet. So, we have described another cultural layer of Tyutchev's poem (and his creativity on the whole).

\subsection{Text and Idiostyle}

The next layer is the key notion of literature: idiostyle. We will understand idiostyle as the author's authentic worldview, and the specific artistic ways of its linguistic realization. For example, if you turn to the notion of "chaos", which is found in many Tyutchev's poems, it is important to note that along with the cultural contexts, which we have already discussed in this paper, this concept also contains a unique, author's meaning. Certainly, the poet has a special, deeply intimate and even controversial attitude to chaos. For him it is causes the fearful abyss, which can absorb the person at any time (...We're sailing, surrounded by the inflamed abyss ...), and at the same time it is some ancient magic power close to the poet's soul (...don't sing those fighting songs about the ancient chaos, about the native ...) This idea of the native chaos is very important for understanding the meaning of Tyutchev's lyrics. This may be one of the individual author's interpretations of the "world soul" concept, which reflection is the human soul. Maybe it's the "Elysium of shadows", which a person spontaneously subconsciously feels in his soul, but which exists only in the form of chaos, rather than as a harmonious order. This interpretation of the "chaos" category makes us study the key motives of Tyutchev's lyrics, to its crosscutting images and symbols. Yet that's the next cultural layer, with the review and analysis of a poem in the context of the whole Tyutchev's poetry. At this stage of the contextual, cultural analysis, we face a rather interesting process, which is seen by Y. M. Lotman as "the context turning into the text".

This situation needs to be deciphered. F. I. Tyutchev is one of those few authors whose poetry should be understood holistically in the frame of the whole poetic heritage. In other words, for a person, who read just a few works of the poet, much in them will remain obscure, hidden meanings will not be revealed in full. For the completeness and adequacy of perception one should become familiar with all the works of the poet, which is a 
model of comprehensive philosophical system with the specified forms, general principles of compositional and structural organization, and repeated scenes. Such a task can be handled only a skilled specialist. For example, if you do not know that the basic principle of Tyutchev's poem composing is the principle of antinomies, ethical oppositions it will be impossible to determine functional and semantic significance of the transparent image-symbols of his lyrics. Meanwhile, all epyc images are distributed according to the oppositions as a correlation of the higher (sacral) and inferior (profane) spatial orientation points in the world continuum. The main opposition (human-nature) is covered by its various modifications: Space-Chaos, Up-down, Sublime-Foul, etc. Exactly in this aspect one should consider the artistic images in Tyutchev's poem "There is a certain hour in the night ...": "the sanctuary of heaven" as the sacral top and "chaos on the waters" as an opposing profane bottom. At the same time, if to have no idea of the dialectic character of Tyutchev's philosophical worldview, one will not be able to appreciate the images-opposition as periodically getting close, mutually exchangeable substances. For example, Chaos is the undeveloped space, harmony in the genesis, while the space is what will eventually become chaos. Finally, if not to know about the key motivation behind Tyutchev's lyrics, such as the search of life sense motive, the motive of dreaming, the motive of a man and nature, the apocalyptic motive, etc., it will not be clear where are references to "prophetic dreams", "nude abyss", "heavenly fire" from in a separate poem. All this points to the fact that Tyutchev's lyrics on the whole is some text that should be read adequately received by and evaluated by the reader. In this case, the whole poetic context becomes a unified text of the great poet's life and career.

\subsection{Semiotic Framework of Culture Invariant Components. Image of Rome in F. I. Tyutchev Poetry}

There is another important issue, necessary to mention. Lotman's works, devoted to language and text, contain an indication that the semiosphere as common cultural space has invariant constant components and various temporary elements. It is obvious that thanks to the constants (sustainable cultural images-archetypes) culture can fulfil its reproductive and broadcasting functions. These "eternal" images, wandering from one era to another, becoming a powerful fastening element of all cultural links and the structural principle of the semiosphere. These include the image of Don Juan, and the eternal motive of selling the soul to the devil, and the eternal light and the dark forces' antinomy, and many other. We can find such images with any poet and writer. Tyutchev also has them. In this sense, his poetry is a micro model of the processes, which take place in the culture. Notably, in Tyutchev's creativity, there are invariant and time components and the invariant components provide the poet's link with the experience of the past and future generations. Giving examples, Rome should be mentioned necessarily. Rome, which became a favorite image for many poets and writers, identified with the era of perpetual prosperity and harmony, then over time, with the universal depravity of manners. In Tyutchev's poetry, Rome acquires the features of a beautiful and unattainable ideal. Ultimately, this image becomes Tyutchev's modification of beauty in its purest form:

In the blue night Rome is sleeping

Moon rose and captured him,

And the sleeping city, deserted and grand

Was filled with its silent glory.

How sweetly Rome is dazing in its rays!

How close Rome's eternal dust became too it!..

As if the Moon world and the sleeping city

Are all the same worlds, magic, but anachronistic!.. (Tyutchev, 2004)

This poem is a good example of how epically significant, universally cultural codes-meanings are transformed, decoded in the context of individual author's world model. On the one hand, Tyutchev's image of Rome dates back to ancient traditions and is associated with an ancient representation of Kronos epoch (God Chronos)-the ideal time for the common welfare. As long as in the 8th century BC Hesiod wrote that humanity goes through several stages of development: gold, silver, copper, Iron Age, an age of heroes, an age of monsters. But in the end it must inevitably return to the golden age. Tyutchev accepted this value, but introduced it into the context of his philosophical ideas about the human search for a lost ideal, merging with the divine truth. Thus, the motive of Rome is organically intertwined with the motive of the night. Interestingly, the existence of Rome as an integral part of the secret knowledge of the unseen, according to Tyutchev, is possible only at night. Moreover, the "moon" and "city, the reposed" are shown similar. The poet emphasizes that these are faces of the same beautiful image, unattainable and painfully distant (Sevrjugin, 2002, pp. 180-182). Subsequently, at the beginning of the 20th century, Tyutchev's tradition was accepted by Mandelstam when he addressed the image of the "eternal city". 
However he will more often describe St. Petersburg as the modification of Rome, both "tears-causing familiar", and mysteriously beautiful.

So, we discovered the universal cultural dimension of Tyutchev's poetry. We still need to specify those components of his work, which suggest the combination of poetry language with languages of other art forms. In the theory of literature there are two basic ways of reality reproduction: realistic and modernistic. Despite the fact that Tyutchev was living in the era of "naturalism", he is called the first modernist in literature. To be more precise, many researchers agree that Tyutchev was working at the start of impressionism. We can remind that the literal translation of the word 'impressionism' (from French impressio) is an immediate impression. That's true that, many Tyutchev's poems make an impression of a momentary mental impulse, a sudden strong feeling generated by what he saw. However, the very notion of "a lyrical hero" refers to the sphere of emotions, sometimes alternating rapidly. The course the world's artistic culture tells us that impressionism as a great art style and as a world view principle united different art forms: painting, architecture, music, sculpture, and literature. Thus, Tyutchev's impressionism makes his language a language for different types of art "communication".

\section{Conclusion}

The following conclusions can be made:

1. In the cultural consciousness of a modern man such notions as language, speech, text, sign, semiotics have been treated in a new way and more widely.

2. A comprehensive analysis of the text as a universal cultural and linguistic category can reveal at least two basic approaches to its study: a traditional and a broader one, more associated with the concepts of discourse and semiosphere.

3. At the present stage of linguistic knowledge development text is actively involved into the scope of the study by a range of humanitarian sciences-semiotics, pragmatics, hermeneutics, anthropology, theory of operation, etc. The consequence is a phenomenon, qualified by P. Rieker as the conflict of interpretations; the resurrection or the emergence and development of several new branches of science about language, including the theory of communication, linguo-pragmatics, philological hermeneutics, discursive linguistics etc. The central sense-forming category of the humanitarian knowledge is the combination "a person and his language" in the philosophical sense of this phenomenon.

4. Examination of the fiction texts in the logical and cultural aspect is necessary for the understanding of their semantic many-layers nature.

5. The existence of such a "layered nature" can lead to the problem of semantic interpretation of texts and cause the methodological problems for teachers of Russian literature. Therefore, in the long term it'd be reasonable to focus this scientific direction on the achievement of certain practical results: creating new teaching manuals and recommendations for the study of literature at school; development of new effective methods of linguistic text analysis, active work on dictionaries containing copyright idiostyles (for example, a dictionary of F. I. Tyutchev's concepts-constants).

6. Language and text are critical and inalienable components of culture, outside of which it cannot exist.

\section{References}

Bakhtin, M. M. (1997). The problem of text in linguistics, philology and humanities: the experience of philosophical analysis. Russian literature: Chrestomatiya. Moscow.

Bibler, V. S. (1989). Culture. Dialogue of cultures (the experience of definition). Voprosy philosophii, 6.

Boost, K. (1955). Neue Untersuchungen zum Wesen und zur Strukfur des deutschen Satzes. Der Satz als Spannungsfeld. Berlin.

Borisova, E. G. (2014). The Discourse Words and Reference in the Process of Understanding. Computational Linguistics and Intellectual Technologies. Papers from the Annual International Conference "Dialogue", 13.

Garfinkel, H. (1967). Studies in Ethnomethodology. NY: Englewood Cliffs.

Harris, Z. (1952). Discourse Analysis. Language, 28(1), 1-30. http://dx.doi.org/10.2307/409987

Kheraskov, M. M. (2008). Collected works. M.

Krippendorff, K. (1980). Content analysis. An introduction to its methodology. Lnd.

Lotman, Y. M. (1992). Semiotics of culture and the concept of text (pp. 129-132). Featured articles V. 1.-Tallinn. 
Lotman, Y. M. (1996). Semiotic space. Lotman Y. M. Inside the thinking worlds: A Person. Text. Semiosphere. History. Moscow

Lotman, Y. M. (2000). On semiosphere. M.: St. Petersburg.

Pospelov, N. S. (1960). The syntactic structure of Pushkin's poetic works. Moscow.

Rudnev, V. (1997). A dictionary of twentieth-century culture. Semiosphere, Moscow: Agraffe.

Rudnitskaya, A. P., \& Pletneva, N. S. (2014). Principles of organization of information and communication interaction between government and society through mass media. Science and technologies, 4, 72-81.

Sevrjugina, E. V. (2002). Concept "beauty" in the poetry of F. I. Tyutchev. Philology, 3, 180-182.

Shcherba, L. V. (1957). Selected works on Russian language. M.

Shcherba, L. V. (1974). Language system and speech activity. L.

Skalichka, V. (1967). Asymmetric duality of linguistic signs (pp. 119-127). Prague linguistic circle. M.: Progress.

Turaeva, Z. Y. (1986). Text linguistics. Text: structure and semantics. M.: Prosvetschenie.

Tyutchev, F. I. (2004). Complete collection of works and letters (Vol. 6). Moscow "Klassika".

Vinokur, G. O. (1991). About the language of fiction. Moscow.

Tannen, D. (2012). New York Jewish Conversational Style (Kommunikativnyj stil' nju-jorkskih jevreev). Sociolinguistics and sociology of language (Sotiolingvistika i sociologija jazyka). SPb.

\section{Copyrights}

Copyright for this article is retained by the author(s), with first publication rights granted to the journal.

This is an open-access article distributed under the terms and conditions of the Creative Commons Attribution license (http://creativecommons.org/licenses/by/3.0/). 